\title{
Research on the Training Model of Application-Oriented Undergraduates from the Perspective of "Innovation and Entrepreneurship"
}

\author{
Zhang Beiping, Yuan Huan, and Wang Yong
}

\begin{abstract}
Innovation and entrepreneurship education is the necessary requirement of educational reform and development in the new era, and also an important carrier of cultivating talents with comprehensive quality in application-oriented universities. How to reform the mode of talent cultivation, the content of education and the methods of teaching, so as to strengthen the cultivation of college students' innovative spirit and entrepreneurial ability, has become an important research topic in the reform and development of higher education.
\end{abstract}

Index Terms-Innovation and entrepreneurship, talent training, education style.

\section{INTRODUCTION}

"Innovation and entrepreneurship" education is extremely necessary for current economic society and national development strategy. It is of great practical and long-term strategic significance to develop "innovation and entrepreneurship" education for promoting the development of higher education, deepening the reform of education, improving the quality of talents educated. [1] Opinions on Vigorously Promoting Innovation and Entrepreneurship Education in Colleges and Universities and College Students' Independent Entrepreneurship insured by the ministry of education clearly put forward that "Innovation and Entrepreneurship" education should be geared to all students and integrated into the whole process of personnel training." Therefore, constructing a complete "innovation and entrepreneurship" education system is the basic guarantee of achieving the goal of innovation and entrepreneurship education.

\section{TOP-LEVEL DESIGN OF TRAINING PROGRAM FOR APPLICATION-ORIENTED UNDERGRADUATEDS}

The cultivation of "innovation and entrepreneurship" talents is a systematic project. Colleges and universities are the main battlefield. "It is an important subject for Application-oriented universities that how to cultivate high-quality innovative and entrepreneurial talents. The key is

Manuscript received March 13, 2019; revised May 25, 2019. This work was supported in part by the 2016 Hubei Province Education and Science Project under No.2016GB097.

Zhang Beiping and Yuan Huan are with the Department of Mechanical and Engineering, Hubei Polytechnic University, Huangshi, Hubei, 435003, China (e-mail: zbpin11@163.com, yuanhuan1980@126.com).

Wang Yong is with the Medical Department, Hubei Polytechnic University, Hubei 435003 China (e-mail: WangYong1994@126.com). to do a good job in top-level design of talents training programs.

The cultivation mode of entrepreneurship and innovation talents is driven by both quality and ability and guided by market demand. It aims to cultivate a compound and applied ecosystem of entrepreneurship and innovation talents who can lead social needs, industrial development and industrial reform with innovation spirit and entrepreneurial ability. We can divide the talent cultivation model system into target positioning system, strategy operation system and support system. Those system is supported by proper course design, new way of teaching and professors from different background. As figure 1 shows, the goal is to help students develop the way of thinking combining the angle of different industries. The core is to guarantee the quality of teaching and the staff. Besides, we need an evaluation system in which we judge students from different aspects.

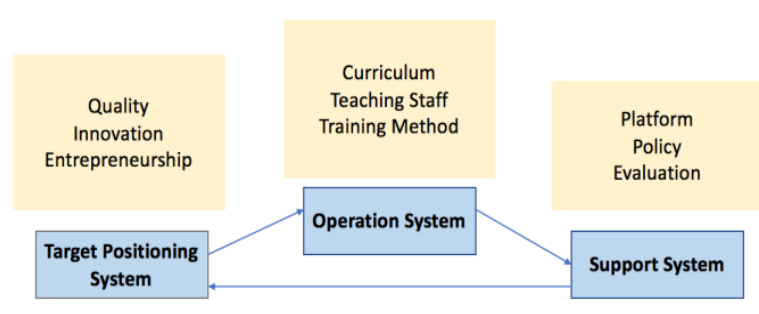

Fig. 1. The talent training system aiming at innovation and entrepreneurship

\section{The TARget OF APPLIED UNDERGRAdUATE TALENTS Cultivation}

Application-oriented university is a new type of universities with the popularization of higher education, whose main body is undergraduate education and the prominent characteristics is applied talents training. As a new form of higher education, Application-oriented universities in China have developed rapidly in quantity, but they are still in the preliminary exploration stage in internal quality improvement. However, the relative lag of the internal quality improvement has affected the quality of education and the future development of these schools in various degrees. As far as the target orientation of applied undergraduate education is concerned, unlike research undergraduate education, the goal of applied undergraduate education is to train advanced application oriented talents with solid foundation of broad knowledge, strong ability and high quality, who are directly engaged in solving practical problems and have innovative spirit and sense of responsibility. The remarkable 
characteristics are that it pays attention to the cultivation of students' skills while strengthening the professional basic education. Therefore, when determining the goal of talent cultivation, application-oriented undergraduate courses should focus on cultivating students' innovative spirit and entrepreneurial ability. Three transformations should be realized when the goal orientation of application-oriented undergraduate talents training is made.

1) Change from knowledge-oriented type to the combination type. At present, the undergraduate education of application-oriented colleges and universities is still in the stage of knowledge-oriented and passive-oriented training. It emphasizes the input of theoretical knowledge and fails to pay attention to the training of students' innovation ability and practical ability, which makes the training of talents fail to effectively meet the needs of society. Talent cultivation should aim at comprehensive quality. The combination of theory and practice can make the students master professional theory knowledge and developing the ability to solve the problems and improving things.

2) Transfer from discipline-oriented to trans-boundary thinking. With the development of social economy, the mutual penetration and integration of industries are expanding in depth and breadth, and the demand for talents is no longer single but compound. Therefore, the cultivation of creative talents should break the professional boundaries of disciplines, carry out "open" interdisciplinary education, broaden students' horizon and expand their knowledge perspective, and cultivate the cross-border thinking of creative talents.

3) Encourage individual development ways. Most of the current talent training system is employment-oriented, and talent training has certain homogeneity. However, under the situation and background of "innovation and entrepreneurship", the development of talent diversification is imperative, and personalized education is the fundamental way to cultivate innovation and entrepreneurship ability. Talent cultivation should be people-oriented, dig deeper into each student's strengths and potential, respect and protect students' personality and needs, and attach importance to students' personality shaping, thinking training, and entrepreneurial potential, which allow the students to foster strengths, pursue their own interests, make full use of their own characteristics, and find their way to success. [2]

\section{OPERATION SYSTEM OF APPLIED UNDERGRADUATE} TALENT

\section{A. Curriculum of Applied Undergraduate Talents}

The content and system of courses embody educational concepts and thoughts, which are the blueprint of implementing training objectives and the main basis of organizing teaching activities. [3] In today's colleges and universities, the design of curriculum system is mostly based on professional theoretical knowledge, and seldom involves the education and training of innovation and entrepreneurship knowledge and ability. As a result, the cultivation of talents in colleges and universities can't keep up with the social demand. College students are weak in innovation consciousness and practice ability. The employment pressure continues to increase.[4] Therefore, in order to fundamentally meet the needs of talent cultivation under the concept of national new economic development strategy, application-oriented universities must pay full attention to the innovation of curriculum system and curriculum content, set up career development and employment entrepreneurship guidance courses and construct a curriculum system integrating professional education and innovation and entrepreneurship education at the center of innovation and entrepreneurship. Innovation education must be integrated into professional education. Without professional education, entrepreneurship education can only stay at a certain level of skills and operation, making entrepreneurship education "water without source and a tree without root". At the same time, professional education should also become the "booster" of "innovation and entrepreneurship" education. The two can complement each other and promote each other. [5] At the same time, professional education should also become the "booster" of "innovation and entrepreneurship" education. The two can complement each other and promote each other. Fig. 2 shows the Course System of cultivation of innovation and entrepreneurship talents with "One Body, Two Wings".

It takes innovation education and entrepreneurship education as the main body, and knowledge, theoretical learning and knowledge application and practice as the wings. The two wings are the way to realize innovation and entrepreneurship education.

1) "Left Wing" includes "entrepreneurship education module" and "innovation education module". "left wing" highlights the core position of the curriculum. It focuses on the cultivation of basic knowledge and basic skills of innovation and entrepreneurship [6], and considers the cultivation of professional ability and innovation and entrepreneurship ability. Entrepreneurship education module" aims to improve the entrepreneurship awareness and enthusiasm of college students by offering entrepreneurship basic education courses (e.g., entrepreneurship awareness and career planning), entrepreneurship ability training courses (e.g., entrepreneurship plan preparation) and entrepreneurship forum.

2) "Right Wing" includes "entrepreneurship practice module" and "innovation practice module". It is a way to apply knowledge to practice, aiming at cultivating college students' innovation and entrepreneurship ability, transforming knowledge into ability and applying theory to practice." right wing" includes "entrepreneurship practice module" and "innovation practice module". It is a way to apply knowledge to practice, aiming at cultivating college students' innovation and entrepreneurship ability, transforming knowledge into ability and applying theory to practice." Innovation practice module" focuses on training college students' innovation and entrepreneurship ability and improving their innovation ability by participating in various discipline competitions at all levels, writing patent and scientific and technological papers and participating in 
teacher projects.

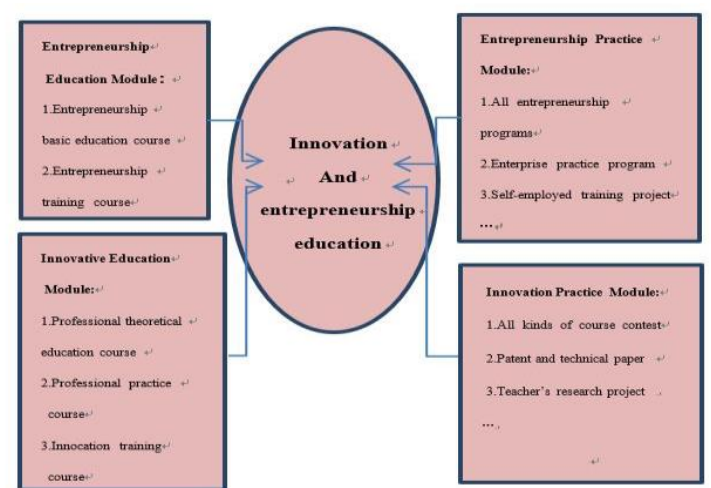

Fig. 2. Curriculum system of "one body, two wings", entrepreneurship and innovation personnel training style.

\section{B. Method of Training Applied Undergraduate Talents}

Aiming at cultivating innovative talents with "innovative consciousness, spirit, thinking, quality and ability" is the essence of innovative education. Developing and improving the "basic quality, consciousness and spirit" of entrepreneurship to form the initial entrepreneurial ability and master the basic skills of entrepreneurship are the main ideas of entrepreneurship education. In order to cultivate high-quality talents with the above two qualities and abilities, it is necessary to change the professional knowledge imparting to innovation and entrepreneurship ability and quality training. It is essential to actively educate and guide college students to explore and practice bravely, so as to cultivate high-level specialized talents who meet the needs of national strategic development and economic and social development.

In terms of teaching methods, we should change the previous teaching methods of "teacher-centered" and "teaching-centered" according to the national strategy of "Innovation and entrepreneurship ". Students are the main body of teaching activities. Through new teaching methods such as discussion, interaction, heuristic, problem-oriented, case-based and research-based methods, students' subjective initiative can be stimulated, so that passive learning is changed into active learning. And students are guided to participate in teaching and research activities. At the same time, a number of comprehensive experimental courses and practical courses and researches with high openness, exploratory and innovative are offered to cultivate students' double creative consciousness, skills and abilities, and project-based teaching is promoted to provide students with more opportunities for scientific research activities, especially independent research exploration. Students' team spirit can be developed, making students' scientific and technological innovative thinking, ability, entrepreneurial quality and ability truly become one of the central contents of education and teaching. At the same time, student should be leaded into professional study, real life practice and comprehensive practice, which includes the two above, and internship.

\section{Construction of "Double Teaching" Teachers}

The cultivation of qualified talents with innovative ideas and abilities is closely related to the quality of the professional teachers. Building a teaching staff with strong engineering practice ability and technological innovation ability, clear division of works and reasonable staff structure are keys to cultivating talents with new and dual-innovation ability. In order to cultivate talents to foster innovation and entrepreneurship, we need a high-level teaching team.

1) Teachers for professional theory courses. It requires high professional theoretical knowledge and rich practical experience, as well as innovative spirit and scientific research ability. Teachers should be mainly engaged in professional theory teaching and scientific research, focusing on imparting professional knowledge to students, cultivating students' innovative thinking and innovation ability, and giving consideration to the cultivation of students' entrepreneurial ability.

2) Professional practice course teachers. Rich practical experience is required. They can be full-time teachers. They can also be hired from the enterprise. They are mainly engaged in the teaching of professional practice courses, focusing on cultivating students' practical ability and entrepreneurial ability.

3) Innovation mentor. They mainly carry out the teaching of innovative education and training courses, and organize innovative societies and various discipline competitions, focusing on cultivating students' innovative spirit and innovative ability.

4) Entrepreneurship mentor. It mainly carries out the teaching of entrepreneurship basic courses and entrepreneurship ability training courses, and guides students' entrepreneurship practice to focus on cultivating students' entrepreneurial enthusiasm and entrepreneurial ability.

5) Industry experts and scholars. They should be often invited to give academic lectures to students to broaden their horizons and focus on improving their comprehensive qualities of innovation and entrepreneurship.

6) Entrepreneurs and successful entrepreneurs. As we all know, successful entrepreneurs, investment experts and professional managers all have certain entrepreneurial experience and innovation ability. They can be employed as part-time professors or invited to hold lectures related to "entrepreneurship and innovation" in our school frequently, so as to continuously diversify and professionalize the faculty of "entrepreneurship and innovation".

The six types of teachers, each to their best, jointly shoulder the responsibility of cultivating innovative and entrepreneurial talents.

\section{THE GUARANTEE OF APPLIED UNDERGRADUATE TALENT}

\section{A. Innovative Teaching Platform}

Based on the goal of innovation and entrepreneurship education, building the carrier of innovation and entrepreneurship education should follow the law of education and teaching, highlight the principle of ability-based, and provide various forms and rich levels of 
support platform for students' developing innovation spirit and improving entrepreneurship ability.

\section{1) Entrepreneurial Cultural Activities}

Developing entrepreneurship cultural activities such as competitions, lectures, forums, mock practices and business visits with the theme of innovation and entrepreneurship are elements of "innovation and entrepreneurship" education. Rich and colorful entrepreneurship related activities will play an irreplaceable role in expanding students' entrepreneurship quality and improving their ability of innovation and entrepreneurship.

\section{2) Entrepreneurship Course}

The course about entrepreneurship is also the important carrier of innovative entrepreneurship education open to all students. By offering entrepreneurship courses, we can achieve the goal of large-scale entrepreneurship awareness and knowledge education under the condition of low investment, which is the most important means to promote the popularization of entrepreneurship education.

\section{3) College of Entrepreneurship}

Enterprise College adopts the mode of school-enterprise cooperation. It introduces enterprise elites into schools to set up classes, which helps because business owners are familiar with the principles of entrepreneurship and understand the essence of marketing.

\section{4) Pioneering Park}

Pioneering Park is the practice carrier of entrepreneurship education and the indispensable supplementary carrier of entrepreneurship curriculum. By applying entrepreneurial knowledge to entrepreneurial practice in Pioneering Park, on the one hand, it can deepen the understanding of entrepreneurial knowledge, on the other hand, it can effectively improve entrepreneurial skills. The Pioneering Park is the carrier of experiential entrepreneurship education. It provides a platform for students with different professional backgrounds to experience the process of entrepreneurship and cultivate the quality of entrepreneurship.

\section{5) Teaching Factory}

Unlike pioneering parks, teaching factories adopt the teaching method of "teacher with apprenticeship", which provides a training platform for students. It is better for students with the same knowledge background to cooperate in projects, to promote their studies through entrepreneurship, and to train outstanding talents with both technology and management.

\section{6) Incubation Base}

The incubation base works on excellent projects from college pioneering park and teaching factories, and re-incubates these projects in a true social environment to ensure that they have strong vitality before they enter the society completely.

From entrepreneurship culture, entrepreneurship curriculum, entrepreneurship park, teaching factory and entrepreneurship incubation base, various forms of educational carriers cover the whole process of innovative enterprises. Innovation and entrepreneurship culture activities are not only an important carrier of "innovation and entrepreneurship" education, but also an entrepreneurship ecological environment, which plays an extremely important role in Entrepreneurship education. Figure 3 shows a step-by-step platform of entrepreneurship innovation system. In this rigorous system, every student can choose the appropriate innovation and entrepreneurship carrier according to their own needs to improve their entrepreneurship quality, knowledge and skills.

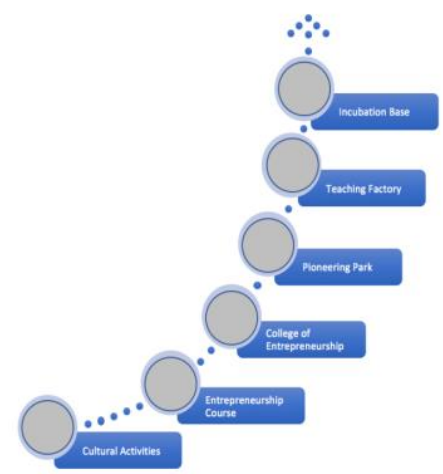

Fig. 3. Innovation and entrepreneurship system platform promoted step by step.

\section{B. Diverse Policy Support}

Innovation and entrepreneurship as a national action plan requires a good atmosphere of social participation. The cultivation of entrepreneurship and innovation talents not only needs the input of schools, but also needs the support of social forces. Diversified policies should be formulated to support the cultivation of entrepreneurship and innovation talents.

1) Capital policy: the establishment of the innovation and entrepreneurship practice platform is based on the integration of social resources, which also requires certain capital and technology support.

2) Incentive policy: on the one hand, excellent students participating in the innovation and entrepreneurship competition and students participating in the internship and practical training will be rewarded to encourage students to carry out social practice activities [7]. On the other hand, a certain subsidy will be given to the various entrepreneurship training carried out by the school to encourage it to provide various entrepreneurship services for college students.

3) Support policies: provide certain policy support to college students who establish innovative and entrepreneurial projects in terms of applying for loans, employment, tax incentives, etc.

\section{Quality and Assessment of Application-Oriented Undergraduate Teaching}

The cultivation of "innovation and entrepreneurship" talents is a process that takes the cultivation of students' innovative and entrepreneurial consciousness as a breakthrough. It takes the cultivation of "innovation and entrepreneurship" spirit and ability as the focus and goal. Quality assessment is not only an important means to ensure the realization of teaching objectives, but also an important link in the teaching process. [8]

1) Reform of Assessment Methods

In the content and mode of curriculum assessment, we should establish the examination criteria with detection ability, quality and innovative as the main factors. We should 
improve the comprehensive assessment methods of students by incorporating the spirit and ability of "innovation and entrepreneurship" into the evaluation index system, by paying attention to examining students' ability to use knowledge analysis and solve problems. We should take students' ability of exploring non-standard answer tests, problem solving ability and creative thinking ability into consideration.

2) Improving the Evaluation System of Education and Teaching Quality

A talent training system, scientific research quality standards, internal control system and evaluation system for application-oriented undergraduate colleges and universities. Learners' practical ability, employment quality and entrepreneurship ability should be taken as the main criteria for evaluating education quality. Serving industry enterprises and serving communities should also be taken as the important contents of performance evaluation. And advanced technology transfer, innovation and transformation application should be the main criteria for scientific research evaluation. Besides, we should improve the database of the undergraduate teaching information, and should issue an annual report of the undergraduate teaching achievement.

3) Make full use of the Industry's Guiding Role

Higher Education institutions should establish periodic publishing systems of human resource demand forecasting, employment situation analysis and early warning of big industry events should encourage and support the planning and guidance of profession. The nature of industry-leading profession should be made full use of industry-leaded teaching, school-enterprise cooperation, and teaching evaluation.

\section{4) Establishing Credit Accumulation and Transfer}

Mechanism

Promote curriculum reform to match the goal of innovation in teaching. Reasonable credit for innovation and entrepreneurship should be set up and be allowed to transfer with the curriculum credit system. Only by this can encourage students to do innovative experiments, publish papers, obtain patents Students' participation in project research and project experiments can also be considered as curriculum learning.

5) Improving the Student Status Management System

To develop innovative entrepreneurship training programs for willing and potential students, innovative entrepreneurship files and transcripts should be made to objectively record and quantitatively evaluate students' innovative entrepreneurship activities. Priority should be given to students who participate in innovative entrepreneurship. They should be allowed to transfer into relevant majors. Flexible education system, length of study, and academic process adjustment, quitting school temporarily for innovative entrepreneurship should be allowed.

\section{CONCLUSION}

As the main battlefield of cultivating innovative and entrepreneurial talents, application-oriented colleges and universities have an inescapable responsibility in it. Therefore, application-oriented undergraduate colleges and universities must attach great importance to the cultivation of innovative and entrepreneurial abilities of college students to open a broad field for the cultivation of innovative and entrepreneurial abilities of College students. As is stated above, with the goal of develop talents with innovation, systematical change of curriculum, teaching staff and training method should be made. At the same time, Platform, policy and evaluation system should be well established to support the operation well. Only by this, by building a good atmosphere, building an innovative stage, can colleges contribute to the cultivation of "innovation and entrepreneurship" talents needed for the core strategy of Chinas.

\section{REFERENCES}

[1] P. K. Fu and P. Liu, "Thought and practice of constructing carrier group of innovation and entrepreneurship education," Journal of Shiyan Vocational and Technical College, vol. 25, no. 3, p. 36, June 2012.

[2] X. Zhou et al., "College innovation education in tourism management," Modern Business, pp. 41-42, 2012.

[3] Y. C. Zhao and W. M. Yang, "Higher education response to the wave of 'mass entrepreneurship and innovation'," Education and Teaching Forum, p. 66, Feb. 2016.

[4] N. Yang, “'Innovation and entrepreneurship' talent training mode In the example of e-commerce," Talents, Pp. 77-78, December 2015.

[5] J. Q. Wu, "The concept of college encouraging the education of innovation and entrepreneurship," China Education, vol. 3, August 14, 2010 .

[6] V. G. Ivano et al., "Regional experience of students' innovative and entrepreneurial competence forming," Review of European Studies, 2014,

[7] J. Zhou, "The construction of innovation and entrepreneurship training mode", Yangtze University Study Report, pp. 141-143, vol. 34, no. 12, 2011.

[8] J. W. Song et al., "'Double creative' talents training model research and practice - Take electrical professional talents training as an example," Vocational and Technical, no. 158, p. 62, September 2013.

Copyright (C) 2019 by the authors. This is an open access article distributed under the Creative Commons Attribution License which permits unrestricted use, distribution, and reproduction in any medium, provided the original work is properly cited (CC BY 4.0).

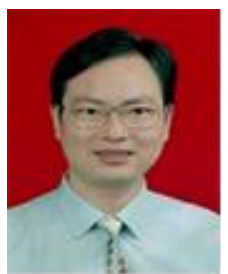

Zhang Beiping was born in Nov. 1965. He graduated from Wuhan University of Technology and gained the master degree in traffic transportation planning and management in June 2005.

He now works as associate professor in Hubei Polytechnic University, Hubei China. He is the author of textbook management and practice of modern logistics, which issued by Peking University Press. His work reasonable stock logistical neuro model based on principal component analysis was issued by logistic technology in March 2006. His work supply chain logistics management based on bar codes technique was issued by China Water Transport (ISSN1006-7973) in April 2006.

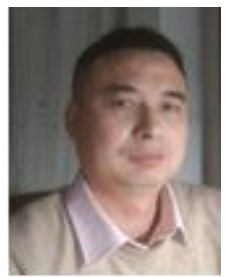

Yuan Huan was born in April 1980. He graduated from Wuhan University of Technology and gained the master degree in mechanical engineering in Dec. 2007. He now works as associate professor in Hubei Polytechnic University, Hubei China. He now devoted in automotive engineering. He is the author of more than 20 papers and the holder of a patent.

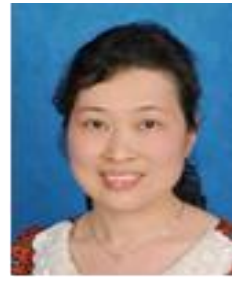

Wang Yong was born in Aug. 1965. She graduated from Yangtze University and gained clinical medicine undergraduate's degree in June 2002. She is the senior lab master in Hubei Polytechnic University, Hubei China, and devoted herself in medical theory related mentoring. 